\title{
LEGAL RESPONSES TO PATIENT INJURY: A FUTURE AGENDA FOR RESEARCH AND REFORM
}

\author{
WALTER J. WADLington* \\ I \\ INTRODUCTION

\section{Past Crises and Responses}

Concern about liability for medical malpractice pervades our health care delivery system. A national data bank mandated by Congress now tracks all paid malpractice claims against physicians as well as information about disciplinary actions. When the Physician Payment Review Commission seeks to reform Medicare fees for physicians, an integral task is computing increments for reimbursing liability insurance premiums. Liability issues can affect medical decisions from obstetrical choice of delivery methods at the beginning of life to a determination whether to withdraw artificial life support at its end.

This preoccupation with liability grew to its present magnitude in a relatively short time. Less than two decades ago, the general public received its first reports about what soon afterward was dubbed the "medical malpractice crisis." Initial pronouncements about its extent and causes varied. In some circles, it was quickly labeled a key contributor to another growing concern-escalation of medical costs. Others saw it as a diversion from more important problems of health care delivery. Pragmatic observers questioned whether there was sufficient information for realistic assessment of the perceived problem's dimensions or etiology, or whether the alleged shortcomings of the tort system were demonstrably greater in the medical malpractice arena than elsewhere. ${ }^{1}$

Copyright (C) 1991 by Law and Contemporary Problems

* James Madison Professor of Law, Harrison Research Professor, and Professor of Legal Medicine, The University of Virginia.

As Director of the Robert Wood Johnson Foundation Medical Malpractice Program, the author has keep abreast of most of the recent research and writing in the area as well as many proposed projects that were never undertaken. However, the views expressed in this article are those of the author and no official endorsement by the Robert Wood Johnson Foundation should be inferred.

1. The literature on the "crisis" is voluminous and varied in perspective. See, for example, Medical Malpractice Insurance and Its Effect on the Delivery of Health Care Services, Hearing before the Subcommittee on Health and the Environment, US House of Rep Commerce Committee, 94th Cong, 1st Sess No 94-130 (June 15, 1975); George L. Priest, The Current Insurance Crisis and Modern Tort Law, 96 Yale LJ 1521 (1987) (evils of crisis). Compare Sylvia A. Law \& Steven Polan, Pain and Profit: The Politics of Malpractice (Harper \& Row, 1978); Tony Dunningham \& Robin Lane, Malpractice-The Illusory Crisis, 54 Fla B J 114 (1980) (skeptics). 
The aura of emergency emanated mainly from problems of obtaining affordable professional liability insurance, especially for physicians in "high risk" states or specialties. The speed with which availability problems arrived remains startling, even in retrospect. As late as January 1973, a commission on medical malpractice appointed by the secretary of the Department of Health, Education and Welfare (now DHHS) reported that

malpractice insurance is currently available to health-care practitioners under group plans and the market for such insurance is competitive. Malpractice insurance is also available to individual health-care practitioners, although they appear to have more difficulty in locating insurance sources. ${ }^{2}$

Soon after the report's release, those conclusions were greeted derisively by physicians in most parts of the country.

Trying to explain what suddenly produced the serious problems of insurance availability became an exercise in passion and conjecture for some and serious introspection for others. Causes most frequently proffered at the time $^{3}$ included changes in the legal system, for example, allegedly "special" rules for health care practitioners; a surfeit of lawyers; insurers' poor investment results; underwriting uncertainty created by long periods between incidents of alleged malpractice and their ultimate judicial or administrative resolution; the medical community's inadequate "self-policing" against the "bad apples" (often described as less than 10 percent of practitioners who generated a disproportionate number of claims); increased likelihood of medical injury resulting from new technology and more complex medical practice; declining medical practice standards and deterioration in the traditional physician/patient relationship; excessive costs of the existing liability compensation system; and alleged popular conviction that patients experiencing untoward results beyond their control should be compensated. Aside from the obvious inconsistencies among some of those asserted explanations, their diversity illustrates the general confusion about what was happening. This flailing about causes was soon to give way to flailing about solutions.

Perhaps the more interesting question was how the crisis actually affected the medical profession. Very demoralizing and damaging results quickly were cited, many based largely on anecdotal information. These complaints included increased costly "defensive" medical practices; decreased willingness to perform needed but "high risk" procedures (sometimes termed "negative" defensive medicine); "going bare" (practicing medicine without liability insurance); and "dropping out" of medical practice partially or entirely.

2. See Department of Health Education and Welfare ("HEW"), Report of The Secrelary's Commission of Medical Malpractice (January 16, 1973).

3. For a sensitive review of what occurred during the period, see Glen $\mathrm{O}$. Robinson, The Medical Malpractice Crisis of the 1970's: A Retrospective, 49 L \& Contemp Probs 5 (Spring 1986). For an early, perceptive review of reform alternatives, see Kenneth S. Abraham, Medical Malpractice Reform: $A$ Preliminary Analysis, $36 \mathrm{Md} \mathrm{L} \mathrm{Rev} \mathrm{489,490-95} \mathrm{(1977).} \mathrm{For} \mathrm{a} \mathrm{general} \mathrm{perspective} \mathrm{on} \mathrm{the} \mathrm{origins} \mathrm{of} \mathrm{the}$ medical malpractice crisis, see Fred C. Zacharias, The Politics of Torts, 95 Yale L J 698, 718-22 (1988). 
Many of the most urgent legislative responses involved what was described aptly as "tinkering" with the tort system, although many states also addressed issues of insurance or medical quality control. ${ }^{4}$ Most responses focusing on the legal system could be distinguished by whether they modified or abrogated previous tort rules, introduced new procedural hurdles for claimants and their attorneys to jump, or were aimed at reducing the size of awards or the number of claims. At least two dozen types of legal changes were enacted: Widely adopted reforms included imposing ceilings or "caps" on damages; modifying the collateral source rule to prevent multiple recoveries for the same injury; limiting contingent fees; introducing pretrial screening or review procedures; restricting ad damnum clauses in complaints; adding new rules for application of the doctrine of res ipsa loquitur; promoting arbitration; requiring certification of the meritorious character of a claim before instituting legal action; mandating or promoting periodic or structured damage awards; shortening statutes of limitation; and codifying the doctrine of informed consent. ${ }^{5}$ A swarm of constitutional challengers turned to the courts; there were some significant casualties but most provisions survived judicial scrutiny, often owing to judicial deference to legislative proclamations of crisis. ${ }^{6}$

This first wave of reforms tapered off about 1977. The succeeding lull featured far less concern about malpractice liability, a response reflecting slower growth and even some declines in claims frequency. ${ }^{7}$ A new round of state legislative activity began in the middle 1980 s as the claims experience again became threatening and the broader liability insurance market saw availability problems of the sort doctors had experienced in the 1970s. There was further tinkering with the tort system, consisting largely of the adoption of earlier reform measures by states that had not done so in the $1970 \mathrm{~s}$, as well as attempts by first-round reformers to fine tune what they had in place. There was also continued attention to initiating measures involving medical quality control and insurance, ${ }^{8}$ and this round of reform saw enactment of

4. Changes in the latter category included encouraging peer review, expanding protection from actions against physicians participating in peer review, instituting risk management procedures, and expanding disciplinary powers of agencies regulating medical and hospital practice.

5. For detailed contemporaneous listing and assessment, see Kandy G. Webb, Recent Medical Malpractice Legislation-A First Checkup, 50 Tulane L Rev 655 (1976); Comment, An Analysis of State Legislative Responses to the Medical Malpractice Crisis, 1975 Duke L J 1417 (authored by Betsy I. Carter, et al).

6. A typical legislative package included a "finding" that there was an emergency situation calling for stern measures to assure continued access to basic health care. Courts continue to pay attention to such statements. See, for example, McGibony v Florida Birth-Related Neurological Injury Compensation Plan, 564 So 2d 177, 178-79 (Fla App 1990) (upholding Florida's no-fault scheme for certain birth-defective injuries). After reviewing the legislative history determining existence of a crisis, the trial court found that the Act was a rational response.

7. The likelihood that the recent changes had contributed significantly to any change in claims seems unrealistic because most of the recent changes had not been in place long enough.

8. For further elaboration of the reform agenda of the $1980 \mathrm{~s}$, see Randall R. Bovbjerg, Legislation on Medical Malpractice: Further Developments and a Preliminary Report Card, 22 UC Davis L Rev 499, 532 (1989). For a negative assessment of the efforts of malpractice tort reform to date, see Peter C. Carstensen, Two Causes for the Predictable Failure of Contemporary Tort "Reform": Naive Analysis and Ignorance of Institutional Interaction, 4 Detroit Coll L Rev 975, 975 (1987) (noting that "only 
specific federal legislation. The Health Care Quality Improvement Act of $1986^{9}$ laid the groundwork for the recently operational national data bank that receives reports of malpractice settlements and significant disciplinary actions against physicians. ${ }^{10}$ Congress also extended the Product Liability Risk Retention Act of 1981 to include medical malpractice, which allowed pooling of liability interests of insureds with comparable risks through "risk retention groups." 11

Debate over malpractice in the 1980s differed significantly from the 1970 s. It was characterized by a recognition that medical injury problems are not simply a function of shortcomings in the legal system. Participants also called for more innovative responses. Law-related reactions in two states extended well beyond "tinkering" and could be classified as radical in comparison with earlier steps. First Virginia ${ }^{12}$ and then Florida ${ }^{13}$ acted to ease insurer and physician fears of unusually high judgments for certain infants suffering permanent and severe neurological injury through the delivery process. They replaced traditional lawsuits with narrowly circumscribed "no-fault" schemes for that limited purpose. The key impetus in Virginia was fear that obstetrical services would be sharply curtailed, particularly in rural areas, after underwriters signaled that new policies for obstetricians would not be issued without some relief. ${ }^{14}$

Recent stabilization and even decline of medical malpractice insurance rates has led some reporters to deviate from previously gloomy accounts. A few seem ready to pronounce the last rites over the crisis ${ }^{15}$ without recalling the similar hiatus between the bouts of the 1970s and 1980s. Though it is too early to know whether recent underwriting results signal the start of a longer trend or a momentary blip in a historically cyclical market pattern, speculation already has begun about reasons for the recent reversal. New explanations include expanded protocols for medical practice, improved quality control through risk management, improved physician-patient communication, and delayed impact of reforms on liability premiums.

legislators and other professionally myopic optimists would claim that any positive and lasting change" has occurred).

9. 42 USC $\$ \S 11101,11111-11152$ (Supp 1988).

10. See id $\$ \S 11131-11137$. The Act also provides for immunity from antitrust liability for professional review actions when certain requirements have been met. Id $\$ 11111$ (a). For further discussion, see James F. Blumstein \& Frank A. Sloan, Antitrust and Hospilal Peer Review, 51 L \& Contemp Probs 7, 82-86 (Spring 1988).

11. Risk Retention Amendments of 1986, Pub L No 99-563, 100 Stat 3170 , codified at 15 USC $\S \S 3901$ et seq (Supp 1991).

12. Va Code $\S \S 38.2-5000$ et seq (Michie, Repl Vol 1990). The Act already has been amended substantially since its original enactment. For further description of the Act, see note 81 .

13. Fla Stat $\$ \S 766.301-316$ (Supp 1991).

14. For differing views about the Virginia approach as well as insights about its enactment, see Richard A. Epstein, Market and Regulatory Approaches to Medical Malpractice: The Virginia Obstetrical NoFault Statute, 74 Va L Rev 1451 (1988); Jeffrey O'Connell, Pragmatic Restraints on Market Approaches: $A$ Response to Professor Epstein, 74 Va L Rev 1457 (1988); Cynthia A. Gallup, Can No-Fault Compensation of Impaired Infants Alleviate the Malpractice Crisis in Obstetrics?, 14 J Health Pol, Pol'y \& L 691 (1989).

15. See, for example, Robert Pear, Insurers Reducing Malpractice Fees for Doctors in U.S., NY Times Al col 1 (September 23, 1990). 
The preceding catalogues of contemporaneous explanations and legislative responses could be expanded considerably. But this limited account should give sufficient perspective on the suddenness of demands on legislatures, the deep disagreements about causes and effects, and the diversity of state reforms. This article is not another polemic about crises and causes. Instead it examines our current understanding of the maze of issues surrounding legal responses to medical injury, our present position on a continuum of reform, and some directions in which we might next proceed.

\section{A TIME FOR RefLection}

After staccato bursts of legislative activity and considerable rhetoric, we have entered a calmer period. Malpractice is gone from the front page for now. Although this period's duration is uncertain, it affords us time to reflect on the nature of malpractice problems and on the different attitudes toward them. But there remains considerable concern about the legal processconcern that extends well beyond the cyclical nature of insurance problems. There is also growing appreciation that malpractice issues transcend the legal system and are deeply entwined with medical practice and complex issues relating to our health care delivery system. For some members of the medical profession especially, the present period is also a time of disillusionment about the utility of legal reforms.

\section{A. Greater Understanding Through New Information}

Because many past legislative responses were crafted with scant knowledge about the nature and dimensions of the problems they sought to remedy, predicting whether they would succeed was an exercise in guesswork. The recent increase in information and analysis enhances prospects for tailoring future changes to accomplish desired goals. This new understanding extends to the nature and extent of the problems that must be confronted, the relative effectiveness and unexpected results of malpractice-driven modifications, and how the tort system functions in the context of malpractice. ${ }^{16}$

A study conducted in California hospitals in 1974 raised many eyebrows with its finding that 4.65 percent of inpatient hospital stays produced medical injuries. All of these would be potentially compensable under a full no-fault scheme, which the authors deemed too expensive at that time. However, 17 percent of the 4.65 percent were found to have resulted from negligence. ${ }^{17}$

16. A number of significant studies were funded by The Robert Wood Johnson Foundation, which in 1986 initiated a Medical Malpractice Program to sponsor research dealing with the impact of medical malpractice on health care delivery. Surprisingly little funding had been made available for such projécts previously, and the Program's goal was to encourage research and demonstrations dealing with medical practice issues, health care organization and management issues, and legal and insurance issues.

17. Don Harper Mills, John S. Boyden, Jr. \& David S. Rubsamen, eds, Report on the Medical Insurance Feasibility Study (Sutter, 1977). 
This was 1 percent of the total cases, larger by a ratio of ten to one than the equivalent claims filed for this period. ${ }^{18}$ Until recently, this finding was the only evidence about the true extent of negligent injury and the shortfall in claims under the legal system. However, a similar New York study of 1984 hospital records ${ }^{19}$ estimated the incidence of adverse events-whether caused by negligence or not-at 3.7 percent. Of those, 27.6 percent (again, one percent of all hospital discharges) were found to have been due to negligence, eight times as large as the equivalent class of claims. ${ }^{20}$ These findings confirm that the dimensions of the medical injury problem remain large, and indeed that the current legal system sees only a small tip of the proverbial iceberg. The information also can be of great importance in assessing the economic feasibility of any scheme that would extend compensation to injuries based on non-negligent conduct.

Growing empirical evidence also exists as to the impact of reform efforts. The passage of time and increased analytic attention have shown that a number of legal reforms work as intended, reducing claims payments and premiums. Other research has evaluated the impact of specific changes in legal rules. In an earlier symposium in this journal, ${ }^{21}$ Professor Patricia Danzon assessed the impact of various reforms. She noted that damage caps had been the most effective response to claims severity. Of reforms limiting frequency growth, shorter statutes of limitation seemed to have had the greatest effect. She also found that arbitration increased claims frequency but held down severity. Most reforms (for example, screening panels and limits on contingent fees) had little impact on either frequency or severity of claims. Other prominent researchers have found similar results, ${ }^{22}$ also extending them to more recent claims data and to effects on premiums. Although one's conclusion after reviewing such studies is that some tort reforms have helped slow the growth of liability costs, reforms of this type hardly can be considered a long term solution given the number of negligent injuries that may yet become the subject of claims. Moreover, some of the past steps seemingly have simply been ineffective.

We also better understand how the liability system works and its impact on the medical profession. What previously had been suspicions or assumptions that malpractice concerns influence specialty choices (most notably to enter or

18. For further appraisal of these findings and their implications, see Patricia M. Danzon, Medical Malpractice Theory, Evidence, and Public Policy 19-29 (Harvard U Press, 1985).

19. Harvard Medical Practice Study, Patients, Doctors and Lawyers: Medical Injury, Malpractice Litigation, and Patient Compensation in New York (Harvard U Press, 1990).

20. Id at 3 .

21. See Patricia M. Danzon, The Frequency and Severity of Malpractice Claims: New Evidence, 49 L \& Contemp Probs 57, 78-79 (Spring 1986).

22. See Frank A. Sloan \& Randall R. Bovbjerg, Medical Malpractice: Crises, Responses and Effects, Health Ins Ass'n Am Res Bull 18-24 (May 1989); Frank A. Sloan, Paula M. Mergenhagen \& Randall R. Bovbjerg, Effects of Tort Reform on the Value of Closed Medical Malpractice Claims: A Microanalysis, $14 \mathrm{~J}$ Health Pol, Pol'y \& L 663-89 (Winter 1989); see generally Stephen Zuckerman, Randall R. Bovbjerg \& Frank A. Sloan, Effects of Tort Reforms and Other Factors on Medical Malpractice Insurance Premiums, 27 Inquiry 167 (1990). 
leave obstetrics) have been at least partially confirmed, ${ }^{23}$ though how seriously this has affected the availability of services is unclear. Other evidence indicating how liability concerns have affected physician willingness to perform certain procedures combine to further illustrate the pervasive impact of concern about malpractice. ${ }^{24}$

With respect to the process of litigation, recent evidence suggests that juries probably are better decisionmakers than previously supposed. ${ }^{25}$ Certainly, some perceived horribles-such as the wholesale imposition of punitive damages ${ }^{26}$-are not major issues. Nonetheless, the increased documentation of the system's functioning does reveal serious concerns that could be addressed through creative procedural responses.

It is also becoming clearer that legal changes alone cannot resolve all the serious problems of medical injury. Studies focusing on non-legal reforms have found that introduction of protocols in areas such as anesthesiology ${ }^{27}$ or emergency room handling of patients with symptoms of myocardial infarction ${ }^{28}$ can reduce claims (by reducing injury as well, one hopes). And a recently completed review of a large body of closed claims stemming from the handling of high-risk pregnancies should enable development of educational interventions to improve the level of care in such circumstances. ${ }^{29}$

23. See, for example, Roger Rosenblatt, et al, Why Do Physicians Stop Practicing Obstetrics?: The Impact of Malpractice Claims, 76 Obstetrics and Gynecology 245 (1990); Institute of Medicine, The Effects of Medical Professional Liability on the Practice of Obstetrics, in 1 Medical Professional Liability and the Delivery of Obstetrical Care 73 (Nat'l Acad Press, 1989) ("The Practice of Obstetrics").

24. For a review of the information and the results of a survey by the American College of Obstetricians and Gynecologists, see Institute of Medicine, The Effects of Medical Professional Liability on the Availability of Obstetrical Providers, in 1 Medical Professional Liability and the Delivery of Obstetrical Care 3553 (Nat'l Acad Press, 1989). Indicators make a strong case that women in rural areas or with low incomes are affected most. See Dana Hughes, et al, Obstetrical Care for Low-Income Women: The Effects of Medical Malpractice on Community Health Centers, in Victoria P. Rostow \& Roger J. Bulger, eds, 2 Medical Professional Liability and the Delivery of Obstetrical Care 59 (Nat'l Acad Press, 1989); Deborah LewisIdeman, Medical Professional Liability and Access to Obstetrical Care: Is There a Crisis?, in Victoria P. Rostow \& Roger J. Bulger, eds, 2 Medical Professional Liability and the Delivery of Obstetrical Care 78-96 (Nat'l Acad Press, 1989); Sloan \& Bovbjerg, Health Ins Ass'n Am Res Bull at 33-35 (cited in note 22). See generally Institute of Medicine, The Practice of Obstetrics (cited in note 23).

25. See, for example, Thomas B. Metzloff, Resolving Malpractice Disputes: Imaging the Jury's Shadow, 54 L \& Contemp Probs 43 (Winter 1991); Stephen Daniels \& Lori Andrews, The Shadow of the Law: Jury Decisions in Obstetrics and Gynecology Cases, in Victoria P. Rostow \& Roger J. Bulger, eds, 2 Medical Professional Liability and the Delivery of Obstetrical Care 161 (Nat'l Acad Press, 1989).

26. See, for example, Mark Peterson, Susan Sarma \& Michael Shanley, Punitive Damages: Empirical Findings 13-14, Tables 2.5, 2.6 (RAND, 1987) (punitive damages awarded in only $2 \%$ of the malpractice cases tried in San Francisco and Cook County from 1980 to 1984).

27. This study on whether imposing specific practice standards for patient care improves medical outcomes and reduces malpractice claim risk for anesthesiologists was conducted at Stanford University by Doctors John P. Bunker and Eugene Dong (Robert Wood Johnson Foundation grant number 12409), with data for a ten-year base line study provided by two doctor-owned carriers representing some 500 anesthesiologists and 500 obstetricians. (Robert Wood Johnson Foundation Grants that have not been completed or for which research findings have not yet been published will be cited subsequently according to the Foundation's grant number.)

28. See, for example, Frank T. Flannery, et al, Abstract: Chest Pain in the Emergency Department, 19 Annals Emergency Med 608 (May 1990).

29. This two part study is being conducted at the University of Minnesota by Doctors Edward Ciriacy and Doris Brooker (Robert Wood Johnson Foundation grant number 12407). 


\section{B. Further Needs for Information and Analysis}

Some important questions still remain only partially answered. Given our increased knowledge about the unexpectedly high frequency of negligently caused injury, one need is for greater understanding about why malpractice occurs. Some studies now under way are seeking early indicators to identify physicians who are prone to malpractice so that timely interventions or strategies for avoidance can be introduced. ${ }^{30}$

Significant among findings of the California and New York studies is that cases of medical injury from negligence vastly exceed claims for liability compensation. This points up our need to know more about the "claiming behavior" of patients. Little is understood about what influences some to bring claims and others not to do so. Two substantial studies of this sort are near completion, one focusing on several surgical services and the other involving orthopedic, emergency, and obstetrical care. ${ }^{31}$ Although the subject is of great importance, information is difficult to obtain, and devising appropriate methodology for studies likely to produce "hard" data is challenging. The availability of workable models in the current studies could help encourage others to explore this area further.

There is special need to clarify the extent of "defensive medicine" and its impact on health care. Despite widespread willingness to admit that significant defensive medicine exists, there is little agreement about its extent or even its definition. A 1987 American Medical Association estimate of some $\$ 12$ billion dollars of extra services in $1985^{32}$ is being used by some as the engine to drive different approaches to reform based on need for cost containment. A key question about any such estimate is the reliability of the information on which it is based. Even those who are willing to accept large cost projections are sometimes cynical about how many procedures are undertaken for economic benefit in addition to their possible legal utility. Some lawyers also believe that defensive practices often stem from physicians' misunderstanding of the law, which could be remedied by better educating doctors on the subject.

30. Studies currently near completion are being conducted at the Oregon Foundation for Medical Excellence (Robert Wood Johnson Foundation grant number 14044, Dennis J. Mazur, principal investigator), and at the Johns Hopkins University School of Hygiene and Public Health (Robert Wood Johnson Foundation grant number 12419, Stephen Teret. principal investigator). Research by Roger A. Rosenblatt and others associated with the Department of Family Medicine, University of Washington, is developing strategies that would focus on reducing probability of negligence in obstetrical care in order to increase the number of providers willing to extend care to socially vulnerable populations (Robert Wood Johnson Foundation grant number 14046).

31. The study of surgical patients is being conducted through the Department of Surgery, University of Chicago (Robert Wood Johnson Foundation grant number 473-ABC, with further support from the American Bar Foundation). It is reviewing experience in a burn center, an intensive care unit, and a surgical floor. A study at the Health Policy Center, Vanderbilt Institute for Public Policy Studies, Vanderbilt University is focusing on birth-related, orthopedics, and emergency-room related injuries (Robert Wood Johnson Foundation grant number 14045).

32. This seems to be the only systematically generated quantitative estimate. See Roger A. Reynolds, John A. Rizzo \& Martin L. Gonzalez, The Cost of Medical Professional Liability, 257 J Am Med Ass'n 2776-81 (May 22/29, 1987). For an analysis of this study, see Sloan \& Bovbjerg, Health Ins Ass'n Am Res Bull at 25 (cited in note 22). 
Another major problem with using any estimate is that there is no broad agreement on what constitutes "undesirable" defensive medicine. Much of what some might include within the rubric of defensive medicine might be considered effective quality assurance measures by others. In its most pejorative sense, a definition would encompass only those interventions or procedures undertaken for the sole purpose of safeguarding providers from the threat of malpractice claims rather than promoting the health of patients. Such activities would indeed be wasteful, unethical, and perhaps illegal. ${ }^{33}$ But as one begins to enlarge the definition, it quickly shades into issues of cost containment and determination of whether the incremental cost is justified for certain expensive procedures that indeed give better, albeit marginally important, diagnostic information. The definition should further include what is known as "negative" defensive medicine, that is, societal costs of health care providers turning some patients away or curtailing or abandoning practice. Although obtaining reliable information about this would be difficult, it would seem necessary for assessing the true impact of the tort system on health care.

Better understanding of all these issues is important. This will require not only funds but assurances of continuing access to sources of information. Some providers and insurers holding such data have been reluctant to allow its use "out of house" even with promises of confidentiality from nonpartisan researchers, perhaps reflecting a new category of "defensive record keeping." In other cases, cooperation may be regarded as an unnecessary bother or expense that is unlikely to assist in their normal operations.

Although legal scholars recently have also paid increased attention to medical injury compensation schemes in other countries, ${ }^{34}$ this remains an area where further review of the experience could be fruitful for further deliberations in the United States. One value is that they allow a look at schemes already in place, sometimes in countries with legal systems similar to our own. ${ }^{35}$

\section{New Appreciation of Limitations of the Tort System}

We also have learned through experience that the tort system has limited utility for dealing with some areas of medical malpractice. A great strength of

33. Some state legislatures have enacted specific prohibitions. See, for example, Fla Stat Ann $\$ 766.111$ (West, 1991), which provides that "[n]o health care provider . . shall order, procure, provide, or administer unnecessary diagnostic tests, which are not reasonably calculated to assist the health care provider in arriving at a diagnosis and treatment of a patient's condition." Violation is a ground for disciplinary action, and one who prevails in an action based on violation of the law can recover attorneys' fees and costs. Id.

34. See, for example, Walter Gellhorn, Medical Malpractice Litigation (U.S. -_Medical Mishap Compensation (N.Z.), 73 Cornell L Rev 170 (1988); Marilyn M. Rosenthal, Dealing With Medical Malpractice: The British and Swedish Experience 174-86 (Duke U Press, 1988); Patricia M. Danzon, The "Crisis" in Medical Malpractice: A Comparison of Trends in the United States, Canada, the United Kingdom and Australia, 18 L Med \& Health Care 48 (Spring-Summer 1990).

35. Donald N. Dewees, Michael J. Trebilcock \& Peter C. Coyte, The Medical Malpractice Crisis: $A$ Comparative Empirical Perspective, 54 L \& Contemp Probs 217 (Winter 1991). 
the common law, as exemplified in the tort system, has been its ability to respond to change. This attribute stems from development and application of principles and standards, rather than rigid rules, to reflect changes in custom and technology. But change that occurs too rapidly may not be mirrored in custom without substantial time lag, and procedural delays now common in our legal system can complicate the problem of determining the standard that was applicable at a particular time in the past. Explosive change in medical technology and increasing scientific knowledge in recent years have tested the tort system's capacity for timely and effective response.

Despite this, the tort system probably has served a greater role in upholding standards of quality than has generally been credited. ${ }^{36}$ When other control procedures are lacking or inadequate, the tort system provides a mechanism through which "reasonable" standards can be determined and enforced. What is described as the system's deterrent factor thus can play a significant factor in medical quality control, though it may be of declining importance because of reinforced disciplinary procedures and more effective institutional and peer review practices.

There is also reason to assert that the tort system on occasion has been expanded beyond its traditional roles of compensation and quality control. Perhaps the best example is the development of the informed consent doctrine, which can be described as an attempt to use the tort system to modify medical mores to increase the opportunity for meaningful patient participation in medical decisionmaking. ${ }^{37}$ By recognizing a physician's duty to disclose to a patient both alternatives to treatment and significant risks associated with a particular course of treatment, courts cast the doctrine in a negligence mold. Many physicians responded that they had been singled out for a duty not applicable to other professionals; they further complained that the law's criteria for determining what they must disclose was so nebulous as to be unworkable.

Eventually, most courts adopted the more restrictive approach to determining whether a patient who had not been given sufficient information would have undergone a particular procedure with such knowledge (a necessary element of proof to satisfy the causation requirement of negligence). The majority standard is what a "reasonable patient" would do if well informed, rather than what the particular claimant would have done. ${ }^{38}$ This approach has the practical effect of limiting the number of actions based

36. Orley H. Lindgren, Ronald Christensen \& Don Harper Mills, Medical Malpractice Risk Management Early Warning Systems, 54 L \& Contemp Probs 23 (Spring 1991).

37. For general background about the purpose and development of this doctrine, see 1 President's Commission for the Study of Ethical Problems in Medicine and Biomedical and Behavioral Research, Making Health Care Decisions: A Report on the Legal and Ethical Implications of Informed Consent in the Patient-Practitioner Relationship (US Gov't Printing Office, 1982).

38. The author's suggestion that the informed consent doctrine may have placed undue strains on the tort system is not meant as a retraction of his belief that it is highly desirable to increase patient information and participation. Walter J. Wadlington, Breaking the Silence of Doctor and Patient, 93 Yale L J 1640 (1984). But to afford genuine individual autonomy, it seems necessary that disclosures consider the individual patient's idiosyncrasies, an important factor that soon was 
solely on lack of informed consent. ${ }^{39}$ The most significant consent cases under the majority interpretation are those involving high-risk, elective procedures. ${ }^{40}$ In addition to this judicial gloss, many state legislatures adopted provisions limiting or prohibiting challenges by patients who acknowledged in writing before treatment that they received adequate information or waived their right to receive it. ${ }^{41}$

The rise and decline of the informed consent doctrine should leave us with serious questions about the limitations of the tort system as a modifier of medical mores. There is little question that the doctrine has been widely misunderstood by physicians. In retrospect, they should not have been expected to distinguish readily between a requirement of obtaining pro forma consent to avoid a battery action and a duty to make appropriate disclosure to avoid a claim based on negligence. In the end, it was the framing of the doctrine in negligence and the law's penchant for fairness of application ${ }^{42}$ that has made liability relatively easy to circumvent, even in instances where a patient might have chosen a different alternative after learning more about alternatives or risks. It is of some consolation that physician/patient communication appears to have improved since the doctrine was introduced. But whether such an experiment in behavior modification of physicians through tort law soon will reoccur is doubtful.

\section{Possible Effects of Evolving Structural Changes in Health Care}

Recognition of the importance of non-legal and non-insurance factors as components of the problem of medical injury points up the need for exploration of how ongoing structural changes in health care delivery can affect medical injury and how it should be compensated.

The complexity of the health care system has not always been recognized or appreciated by legal thinkers. Partly this is because lawyers in the field

\footnotetext{
ignored in judicial treatment of the doctrine. For more review of the informed consent doctrine and its conceptual underpinnings, see J. Katz, The Silent World of Doctor and Patient (The Free Press, 1984).

39. The action for informed consent has sometimes been described as "parasitic" because it is typically an "add on" to an action for negligent performance of a specific procedure. One defense to the basic negligence attack may be that a particular untoward result can be expected in a significant number of cases even when there is no negligence, thus raising the question whether the patient should have been told of that possibility. See, for example, Cobbs v Grant, 8 Cal 2d 229, 502 P2d 1, 104 Cal Rptr 505 (1972).

40. If the alternative is death, the reasonable person probably would choose the procedure even if the possibility of a lesser untoward outcome is known to be expectable. If the goal is purely cosmetic, a reasonable person would be far less likely to assume major risks.

41. Some courts additionally decided that a customary standard of what physicians deem important to disclose will be used to define the scope of the duty. See, for example, Bly $v$ Rhoads, 216 Va 645, 222 SE2d 783 (1976).

42. The ostensible reason for introducing a "reasonable person" standard was the assumption that most patients who unexpectedly suffer untoward consequences from a procedure would in hindsight contend that their "informed" choice would have been different. This, it was argued, might bias a jury determination. The introduction of statutory restrictions was important because proof of whether a person was advised of particular risks and alternatives may be unreasonably difficult to reconstruct after passage of a significant time period. However, critics of some of the statutory provisions point out that the patient who signs a pre-treatment acknowledgement frequently is unable to assess whether he or she has in fact received full disclosure.
} 
often have been narrowly specialized. Relatively few possess such global understanding that they can be expected to appreciate how changes introduced for one purpose might have unanticipated side effects elsewhere. Correspondingly, health care administrators and practitioners generally have been unsophisticated about the legal system. Problems also have been produced or exacerbated by strained relationships and poor communication between physicians and doctors. It would be unfortunate if this lack of breadth and rapport should preclude appropriate consideration of the past decade's major changes in our health care system. For example, the model of physician as "loner" has given way to broad acceptance of group practice. Medical care is viewed widely as a business, and increasingly the health care system is assimilated to a regulated industry.

In the current environment, "buyers" of care, such as insurers, employers, and federal agencies, can considerably influence treatment choices by determining what procedures they will agree to cover and how much they will pay for them. Wide disparity in the economic situation of patients, based both on their assets (and willingness to deplete them) and their insurance coverage (or lack of it), has led some to fear that soon we will have a multitiered health care system sharply differentiated on qualitative bases. In such an environment, fixing standards for purposes of compensation could be even more complex, perhaps resulting in a combination of tort and contract actions to recover for medical injury.

An ongoing development of potentially great import is the erosion of the near-exclusive, standard-setting authority accorded physicians through judicial acceptance of customary standards established by "expert" testimony. Some fear that continuance of this trend not only will generate frictions between doctors, hospitals, and other providers, but also will lead to conflicts with the legal system if courts hearing tort actions apply standards of "reasonableness" that differ from those of third-party payors. Widespread legal clashes may not materialize under the present system, however, because any major reshaping of physician practices might be reflected in the tort system's reliance on custom as the appropriate standard.43 The problems might also be handled through potential extension of liability to third-party payors based on unreasonable limitations on payment authorization. ${ }^{44}$ Such concerns were acknowledged to some extent in a little known (and seldom used) federal statute provision that establishes immunity for conformance with standards set by Professional Review Organizations ("PROs" or "PSROs"). ${ }^{45}$ Recent efforts to establish practice parameters or guidelines,

43. See generally Mark A. Hall, The Defensive Effect of Medical Practice Policies in Malpractice Litigation, 54 L \& Contemp Probs 117 (Spring 1991).

44. For what is regarded as the opening salvo in such an attack, see Wickline v Califormia, $192 \mathrm{Cal}$ App 3d 1630, 239 Cal Rptr 810 (1986).

45. See 42 USCA $\$ 1320 \mathrm{c}-6$ (stating that compliance with a PRO standard should not be considered negligence); John R. Ball, PSRO-An Alternative to the Medical Malpractice System as a Quality Assurance Mechanism, 36 Md L Rev 566 (1977); Henry E. Simmons \& John R. Ball, PSRO and the 
including a legislatively sanctioned demonstration in Maine, illustrate further searches for appropriate responses. ${ }^{46}$

An expectable consequence of characterizing health care as a business is that goals of greater efficiency and effective cost containment are of greater importance. Utilization review and risk management procedures, as well as more sophisticated record keeping systems, have become routine. Reorientation of the liability system, by whatever means, to hold down costs and make them more predictable or to provide more efficient and egalitarian reimbursement for medical injuries, should hold considerable attraction in such an environment. Opportunities to introduce approaches already accepted in other business settings, such as insurance ratings based on experience, ${ }^{47}$ are ample because of their comparatively low use in some parts of the health care market.

Other relevant changes in the health care system include growing fascination with "outcomes research" 48 that is increasingly shared by "buyers" of services as well as health services researchers. Information from such studies might be used in the future not only to determine what procedures should be covered but also to assess whether particular treatments are "reasonable" in terms of establishing a legal standard for negligence. Addition of reporting systems and information banks for malpractice payments and disciplinary actions has increased the information available to hospitals and licensing agencies during the credentialing process. Some of these approaches have the potential to minimize medical malpractice, while others hold promise for replacing the deterrent or "quality control" factor that some fear losing if we depart from a fault-based compensation system. All could contribute significantly to a growing information base that should help in fine tuning past legal responses as well as shaping new ones.

Dissolution of the Malpractice Suit, 6 U Toledo L Rev 739 (1975); Joseph H. King, In Search of a Standard of Care for the Medical Profession: The "Accepted Practice" Formula, 28 Vand L Rev 1213, 1267-75 (1975).

46. Clark C. Havighurst, Practice Guidelines as Legal Standards Governing Physician Liability, 54 L \& Contemp Probs 87 (Spring 1991); Hall, 54 L \& Contemp Probs 117 (cited in note 43). Chapter 931 of Maine Public Law included a general package of legislative responses to medical malpractice concerns. Maine Public Laws ch 931 (West, 1990). Two unusual provisions were a demonstration project for development of "practice parameters" as well as "risk management protocols" for electing physicians from three specialty groups: anesthesia, emergency medicine, and obstetrics and gynecology. Under the Act, the State Board of Registration in Medicine will adopt parameters and protocols under Maine's Administrative Procedures Act. An interesting twist to the legislation is that while a participating physician or that physician's employer may introduce the parameters or protocols into evidence as an affirmative defense, they cannot be used affirmatively against the physician unless he or she raises the issue. See 24 Me Rev Stat Ann $\$ 2975$ (1990).

47. Harold S. Luft, Patricia P. Katz \& Douglas G. Pinney, Risk Factors for Hospital Malpractice Exposure: Implications for Managers and Insurers, 54 L \& Contemp Probs 43 (Spring 1991).

48. See, for example, John E. Wennberg, Outcomes Research, Cost Containment, and the Fear of Health Care Rationing, 323 New Eng J Med 1202 (October 25, 1990) 


\section{III}

\section{Gauging the Climate for Change}

There is no shortage of official and unofficial reports urging further reform. ${ }^{49}$ The Bush administration recognized medical community concern at the highest level recently when the President pledged to help "restore common sense and fairness to America's medical malpractice system." 50

Current attitudes of the medical community are difficult to assess. There seems to be a sense that the legal system is not working properly, even after many changes. Fear of dire financial results from legal claims remains troubling to individual practitioners, and there seems to be increased resentment of what doctors consider legal meddling in medical practice. A continuing sore point is a claims process that many physicians regard as carrying unnecessary and undeserved risk of professional obloquy. But some physicians doubt the likelihood of ever dealing effectively with their principal concerns through the legal system. As a result, interest in reforms more likely to be symbolic than efficacious is waning. ${ }^{51}$

There are also signs of popular dissatisfaction and disillusionment tort reform initiatives, particularly some of the more cost-effective changes engrafted on the tort system for medical injury. Damage "caps" may be unduly limiting awards, and other reforms may be increasing the complexity and cost of litigating claims, that is, limiting the number of claims by elevating the threshold of economic feasibility for attorney representation. Many persons are disturbed, however, that such restrictions may inequitably burden the most seriously injured persons. While it remains popular for physicians to brand contingent fees as a major stimulant to litigation, and many states now limit such compensation, such fees also certainly serve to limit the number of claims by controlling access to the system. ${ }^{52}$ Even when the case for legal liability seems strong, a claim for relatively small damages can be too

49. The General Accounting Office ("GAO") has recommended the development of model state laws that would include some typical malpractice tort reforms that the GAO deemed cost effective. US Gen Acct'g Office, Medical Malpractice, $A$ Framework for Action 19-28, 30-31 (1987). The GAO has also recommended that experimentation with various alternative dispute resolution mechanisms should be encouraged and that demonstration projects to determine their efficiency and efficacy should be funded by the HHS.

Among conclusions of the Institute of Medicine Committee to Study Medical Professional Liability and the Delivery of Obstetrical Care in 1989 were that tort reforms implemented since the mid-1970s were an insufficient response to the special needs of obstetrical care-givers, and that states should begin to focus on alternatives to the tort system. Again it was recommended that federal support should be extended to demonstration projects.

Still another exhortation for further action came in the Report of the Task Force on Medical Liability and Practice (HHS, 1987).

50. This language was reproduced in Amy Goldstein \& Ann Devroy, Bush Urges Malpractice Revisions, Wash Post A8 col 1 (February 23, 1990). A White House task force also has been formed, and the Agency for Health Care Policy and Research is moving toward expanded sponsorship of research and demonstrations on the subject of medical malpractice.

51. For a perceptive discussion of the phenomenon of symbolic reform, see F. Patrick Hubbard, The Physicians' Point of View Concerning Medical Malpractice: A Sociological Perspective on the Symbolic Importance of "Tort Reform," 23 Ga L Rev 295 (1989).

52. This was recognized in the 1973 HEW Report mentioned earlier. See note 2. 
expensive for an attorney to undertake on a contingent fee basis. Nor would an injured person want to employ an attorney on a "billable hours" basis if the cost would approximate or exceed the anticipated recovery. ${ }^{53}$

In Indiana, home of the first broad medical malpractice tort reform package, ${ }^{54}$ strong media criticism recently has been leveled that those provisions have affected injured patients unfavorably. ${ }^{55}$ The attacks have centered on a lethargic claims pace, unfairness of damages awarded to severely injured patients, ${ }^{56}$ and inadequate disciplinary responses. Although the criticism has attracted media attention beyond the state, it is uncertain whether this portends a broader backlash. ${ }^{57}$

Opposition to change should be expected not only from those whose legal specialties could be affected but also from others who question whether a medical malpractice crisis has ever existed or whether some injuries should be treated differently from others because they are medically induced. A "go slow" approach can also be expected from some who are unconvinced that major change, such as instituting a substitute compensation system, is necessary to preserve health care quality and access or that any existing proposals would respond more effectively than the tort system, regardless of its shortcomings.

On balance, it seems probable that there is sufficient interest and momentum at least to initiate some incremental, even evolutionary, changes at this point, if they are not too extensive and do not introduce significant new bureaucracy. Given diminished pressure for further change in some quarters and potential opposition and even backsliding from existing changes in others, the likelihood of major restructuring in the near term seems unlikely unless claims or premiums rise sharply.

53. A further response advocated by some members of the health care industry would tax all costs and attorneys' fees to the loser in malpractice actions (or to the side failing to improve on the last settlement offer). Because this approach could further deter good faith claims with significant chance of recovery, to justify its introduction for medical malpractice alone would in fairness seem to require a showing of special incidence of frivolous claims in the area. Given that a relatively small percentage of medical malpractice cases ever go to trial, and that the percentage of successes among them is not unduly high, such special need seems questionable.

54. See Eleanor D. Kinney \& William P. Gronfein, Indiana's Malpractice System: No-Fault by Accident?, 54 L \& Contemp Probs 169 (Winter 1991).

55. See, for example, Malpractice Law Stacked Against Victims, The Indianapolis Star 1 col 1 (June 26, 1990).

56. Indiana has a damage ceiling for medical malpractice awards that only recently was raised from $\$ 500,000$ to $\$ 750,000$, and all claims above $\$ 100,000$ are handled by a special state commission. According to a study conducted by Professor Eleanor Kinney, actual amounts received by patients suffering high severity injuries seem no lower, and perhaps are higher, than those in neighboring states without comparable damage caps. See Kinney \& Gronfein, 54 L \& Contemp Probs at 181-82 (cited in note 54).

57. The Indiana protests already have received national attention. See, for example, Isabel Wilkerson, Indiana Law at Center of Malpractice Debate, NY Times All col 1 (August 20, 1990). 


\section{A Look at Proposals Under Consideration}

Potential reforms can be characterized along several dimensions. One is the nature of problems addressed. Here, objectives and reforms often focus on (1) inefficiencies of delay, cost, and complexity; (2) the tendency to encourage over-utilization in some cases, while diminishing access to care in others; and (3) the perceived uncertainty and inconsistency of awards. Reform proposals may address all or only some of these elements. Reform efforts can also differ in their expected mode of implementation. Factors here include whether an approach would call for federal or state action (or joint cooperation); whether it could be voluntary or would require legislation (perhaps to create a new administrative scheme); and whether it would be effected by courts or through wholly new systems of investigation and dispute resolution. Other important variables include the underlying conceptual base for providing compensation and the measure and form of compensation. Variables can be adapted in different proposals according to the specific goals desired (lower cost, compensation for more persons, minimizing delays, or simplifying procedures). ${ }^{58}$

Some promising approaches are largely procedural and could be relatively simple to implement. A good illustration is the introduction of specially tailored alternative mechanisms of dispute resolution. ${ }^{59}$ But not all "procedural" changes can be so easily introduced. For example, the AMA/Specialty Societies proposal ${ }^{60}$ would require a major new administrative entity for resolving claims, even though the plan is incremental by virtue of its fault basis and adjudicatory orientation. ${ }^{61}$ The magnitude of the change is justified on the grounds that prior reform efforts, while

58. For greater discussion of the possible variables and how they might be combined, see Kenneth A. Abraham, Medical Liability, A Conceptual Framework, 260 J Am Med Ass'n 68 (1988).

59. Metzloff, 54 L \& Contemp Probs at 104-14 (cited in note 25).

60. . For a description of the proposal and its rationale, see Kirk B. Johnson, et al, A Fault-Based Administrative Alternative for Resolving Medical Malpractice Claims, 42 Vand L Rev 1365 (1989); Elizabeth H. Esty, AMA/Specialty Society Medical Liability Project: A Summary and Explanation of the Proposed Administrative System for Resolving Medical Liability Disputes and Enhancing the Monitoring and Discipline of Medical Practices (Institute of Medicine, July 1988) (contained in Study on the Liability Crisis and its Effects on Obstetrics). To date, probably owing to the magnitude of the suggested changes, no state has enacted the AMA plan. The plan represents such a radical restructuring of the methods by which medical liability is determined that it is difficult to predict how the overall system would operate in practice.

61. The AMA proposal posits the creation of a new state agency called the Medical Practices Review Board (the "Board") to adjudicate medical malpractice disputes. See Tort Reform Codification: Model Medical Liability and Patient Protection Act, 1 Courts, Health Science \& L 87, 93-94, § 202(a)-(b) (Georgetown U Med \& L Ctrs, 1990). The proposal provides for a complex series of investigations, expert reviews, and mandatory settlement procedures, culminating in a hearing in which the claimant is represented by an attorney employed by the Board. Id at 93-99, $\$ \$ 202-208$. In addition to procedural innovations, the proposal includes several modifications of the substantive rules affecting the assertion of malpractice claims, including redefinition of the standard of care, adoption of a causation standard premising liability so long as the doctor's negligence was a "contributing factor" in causing the injury, adoption of the minority rule on informed consent to focus on the adequacy of the disclosure from the patient's perspective, and certain limits on the type or quantum of damages to be collected. Id at 114-18, §§ 400-405. 
ameliorating some of the system's shortcomings, have been employed for over a decade without noticeably improving the system's overall performance. ${ }^{62}$

Another widely discussed approach is known as neo-no-fault. Based on ideas put forward by Professor Jeffrey O'Connell, ${ }^{63}$ this scheme might be implemented voluntarily or legislatively. It would allow a provider to offer payment for all of a claimant's net economic damages (net of all other sources). If made within a specific period after the patient's injury, such an offer would either preempt current access to non-economic damages or allow patients voluntarily to relinquish tort remedies. ${ }^{64}$

Offering providers and patients greater latitude to "tailor" approaches to compensation in advance of medical injury by mutual agreement is an alternative urged persuasively by Professor Richard Epstein, joined by Professor Clark Havighurst, in a series of creative presentations. ${ }^{65}$ Such latitude also should be considered broadly as an alternative for private sector tort reform, though skeptics question whether traditional market factors work in the medical care setting or whether "bargaining" might be so one-sided as to lead to the exploitation of patients. An initial, practical consideration regarding such an approach is that "exculpatory contracts" between provider and patient have been widely rejected in past judicial challenges. ${ }^{66}$ This entrenched jurisprudence makes it likely that wider use of contracting in this area will need legislative approval unless courts finally are prepared to change their views in light of a major trend toward private ordering in other contexts.

Other approaches to reform center on improved risk management ${ }^{67}$ or insurance. ${ }^{68}$ In Part II, it was suggested that the "business" of health care could be expected to become more efficient in its use of insurance methods such as experience rating. ${ }^{69}$ Another approach under discussion would be to relieve physicians of tort liability for hospital-based injury by substituting the

62. Johnson, et al, 42 Vand L Rev at 1376 (cited in note 60) ("These changes have been tried for over a decade in most states without resolving the crisis surrounding the availability and affordability of professional liability insurance."). Interestingly, the AMA proposal eschewed a no-fault solution, finding that it "offends notions of justice and individual accountability by imposing liability on health care providers even when they have done everything humanly possible to treat a patient but were unable to prevent a bad outcome." Id.

63. See Jeffrey O'Connell, Neo-No-Fault Remedies for Medical Injuries: Coordinated Statutory and Contractual Alternatives, 49 L \& Contemp Probs 125 (Spring 1986).

64. A version of such an approach, known as the Moore-Gephardt bill, was introduced in the 98th and 99th Congresses as HR 5400 and HR 3084, respectively. For discussion, see W. Henson Moore \& John S. Hoff, H.R. 3084: A More Rational Compensation System for Medical Malpractice, 49 L \& Contemp Probs 117 (Spring 1986).

65. See, for example, Richard A. Epstein, Medical Malpractice: The Case for Contract, Am Bar Found Res J 87 (1976); Clark C. Havighurst, Reforming Malpractice Law Through Consumer Choice, Health Affairs 63 (Winter 1984); see generally Randall R. Bovbjerg \& Clark C. Havighurst, eds, Medical Malpractice: Can the Private Sector Find Relief?, 49 L \& Contemp Probs (Spring 1986).

66. See, for example, Tunkl v Regents of Univ. of Califormia, 60 Cal 2d 92, 82 Cal Rptr 33, 383 P2d 441 (1963). This rejection has been based at least partly on the "special" role of a provider, which some courts have analogized to that of a fiduciary.

67. Lindgren, Christensen \& Mills, $54 \mathrm{~L}$ \& Contemp Probs 23 (cited in note 36).

68. Luft, Katz \& Pinney, 54 L \& Contemp Probs 43 (cited in note 47).

69. See notes 43-48 and accompanying text. 
hospital as the entity responsible for compensation. ${ }^{70}$ Because a high percentage of claims stem from hospital-based incidents, it is assumed that this change would cover a large segment of significant injuries produced through medical practice. The hospital would meet its financial responsibility through insurance or self-insurance and could benefit from experience rating, which already prevails for hospital responsibility. The latter would provide an incentive for hospitals to "police" their medical staff more effectively. ${ }^{71}$ Other asserted advantages include lessening the stigma that physicians feel is associated with malpractice actions, and handling more evenly the problem of sharp disparities in insurance premium rates according to individual medical speciaities.

An approach that takes a larger initial step than those preceding would be installing a system to compensate without individualized proof of fault for medical injuries listed in advance as "compensable events," 72 a system that stands as a hybrid system between fault and no-fault. Such compensable events are medical injuries that normally occur only infrequently when patients receive good treatment. Listings based on medical avoidability are not unlike considerations of fault, with the very large difference that determinations are made in advance and on an epidemiological basis (avoidability of a class of injuries). Administration would resemble no-faultan insurance-like process rather than a litigious one. Such a system could replace tort law and litigation for many types of injury, but it could not be a total replacement because it would cover only those events categorically established as compensable. This sort of compensation scheme could be introduced legislatively, or possibly through private agreement in jurisdictions where such agreements are not banned by state constitutions or jurisprudence. A key problem in the past has been developing an adequate number of well-defined "events." Current research has used several data bases to confirm the viability of such a scheme. ${ }^{73}$

The most extreme change now realistically under consideration for medical injury compensation would come through introduction of an administratively operated no-fault scheme to replace current tort law. ${ }^{74}$

70. This longstanding idea is sometimes called "channeling" responsibility. For an extended discussion, see Myron G. Steves, Jr., A Proposal to Improve the Cost to Benefit Relationships in the Medical Professional Liability Insurance System, 1975 Duke L J 1305. One such proposal is suggested in the Reporter's Study to the American Law Institute on Enterprise Responsibility for Personal Injury (1991).

71. Hospitals in many states have occupied a larger role in this regard through expansion of the doctrine of corporate liability.

72. This idea originated with Professor Laurence Tancredi joined by Professor Clark Havighurst. For a short history as well as its current status, see Laurence R. Tancredi \& Randall R. Bovbjerg, Rethinking Responsibility for Patient Injury: Accelerated-Compensation Events, A Malpractice and Quality Reform Ripe for a Test, 54 L \& Contemp Probs 147 (Spring 1991).

73. Tancredi and Bovbjerg have adopted the new term "accelerated compensation event" ("ACE"). Id.

74. A Reporter's Study prepared for the American Law Institute suggests that a "no-fault" approach to liability for medical accidents should be regarded as "a serious and plausible alternative in the ongoing debate about how best to deal with medical injuries." However, the study, which was prepared for discussion and does not represent any official position of the Institute, concludes that 
Advantages seen in such an approach are greater process efficiency through timely settlement and greater social efficiency through compensation for far more injured persons. The latter is regarded as important because of the perceived uncertainties today about who can recover and the often difficult and expensive problems of proving negligence. Many physicians favor nofault for de-emphasizing the stigma they associate with a negligence action. ${ }^{75}$ Others oppose it as an enormous expansion of the fiscal responsibility of the medical system. ${ }^{76}$ Though the role of fault is eliminated, implementing such a scheme nevertheless requires case-by-case decisions about medical causation to determine what injuries are covered, and some new entity probably would need to be created for operating it. ${ }^{77}$

A number of suggestions also have been made for structuring a no-fault medical injury scheme along workers' compensation lines. ${ }^{78}$ Major opposition, aside from that by attorneys whose specialties would suffer, likely would be based on potential cost or on concern about removing the tort system's deterrence function.

When the California study was released in the $1970 \mathrm{~s},{ }^{79}$ it was thought that the number of claims that would surface under a no-fault system would make it prohibitively expensive. The New York study ${ }^{80}$ confirms both the high incidence of adverse consequences and the large number of negligently injured persons who do not seek compensation currently. However, in the ten years between the two studies, costs of the liability system escalated to a level that some believe makes introduction of a limited no-fault system at this time economically viable. Its viability would depend on cost savings that could be effected through means such as more efficient claims settlement and substantial reductions in the measure and form of compensation.

such an approach initially can and should be introduced only on a voluntary or "elective" basis. 2 Reporter's Study on Enterprise Liability for Personal Injury 515-16 (Am L Institute, 1991).

75. In an interesting twist to this rationale, it appears that payments made by the commissions administering the Virginia and Florida schemes need not be reported to the national data bank of malpractice claims because there is no finding of liability on the part of the physician involved. 17).

76. Mills, Boyden \& Rubsamen, eds, Report on the Medical Insurance Feasibility Study (cited in note

77. In some instances, a jurisdiction might choose to utilize the agency already administering workers' compensation rather than forming a new administrative organization such as that required by the AMA/Specialty Society proposal. See note 61 and accompanying text. The former pattern is utilized by the limited systems adopted in Virginia and Florida for compensating neurologically birth-defective infants.

78. An interdisciplinary team at the Midwest Institute for Health Care and Law drafted a model medical accident compensation act based along these lines. See M. Martin M. Halley, et al, Medical Malpractice Solutions: Systems and Proposals for Injury Compensation 205 (Thomas Pub, 1989). In Barry Manuel, Professional Liability - A No Fault Solution, 322 New Eng J Med 627 (1990), Dr. Barry Manuel proposed a scheme along workers' compensation lines that would be financed through a surcharge on accident and health policies.

79. See notes $17-18$ and accompanying text.

80. See notes 19-20 and accompanying text. 
No-fault schemes now in place in Virginia and Florida for certain neurologically defective infants are highly limited in scope ${ }^{81}$ and have been operational for only a short time. Unless expanded further, their experiences may be of little help in economic predictions about the costs of a more broadly applicable scheme.82 However, when current constitutional challenges to them have worked through the judicial system, those results could shed important light on the legal vulnerability of such plans in other contexts. What the Virginia and Florida statutes do illustrate is that a more radical system might be introduced to deal with one set of problems regarded as having special impact when a particular level of political pressure for action is reached.

\section{V}

\section{An Agenda for Action}

Given our increased understanding and the likelihood of learning more soon, a next logical step for reformers would be to translate knowledge into action. The current period of diminished pressure for "quick fixes" could afford time for this step to be taken effectively, if funding agencies or entities will recognize the need and promise as well as the special portal of opportunity for fulfilling it that now exists.

Based on past experience, there is concern that the health care establishment seldom willingly embraces major structural change of any sort

81. The limited nature of the Virginia statute is evident in its definition of "Birth-related neurological injury":

injury to the brain or spinal cord of an infant caused by the deprivation of oxygen or mechanical injury occurring in the course of labor, delivery or resuscitation in the immediate post-delivery period in a hospital which renders the infant permanently motorically disabled and (i) developmentally disabled or (ii) for infants sufficiently developed to be cognitively evaluated, cognitively disabled. In order to constitute a "birthrelated neurological injury" within the meaning of this chapter, such disability shall cause the infant to be permanently in need of assistance in all activities of daily living. This definition shall apply to live births only and shall not include disability or death caused by genetic or congenital abnormality, degenerative neurological disease, or maternal substance abuse.

Va Code $\S 38.2-5001$ (Michie, Repl Vol 1990). The scheme is triggered by a claim of "birth-related neurological injury" in a delivery by a "participating physician" or in a "participating hospital." The qualifying infant's legal relief consists of payment for medical, rehabilitative, and residential expenses not reimbursable through other state or federal programs or private insurance; reasonable expenses incurred in filing a claim (including attorneys' fees); and loss of earnings from age eighteen through sixty-five, which are conclusively presumed to be "fifty percent of the average weekly wage in the Commonwealth of workers in the private, nonfarm sector." Id $\$ 38.2-5009$.

Absent clear and convincing evidence that the injury was willfully or intentionally caused, this remedy excludes all others that the claimant otherwise might have against the participating entity. Under the Act as recently amended, if only one entity (hospital or physician) was participating in the program when the injury occurred, a tort action can be brought against the non-participant, but this will be an election not to pursue recovery under the Act; if recovery under the Act is elected, the Program can be subrogated to any malpractice action that could otherwise have been brought against the non-participating physician or hospital. Id $\$ 38.2-5002$.

82. By the close of 1990 , only two cases had been filed under the Virginia Act, and no payments had been made. Six claims had been filed under the Florida Act, and three had been closed with payment. See Walter J. Wadlington \& J. Warren Wood III, Two "No-Fault" Compensation Schemes for Birth Defects in the United States, 7 Professional Negligence 40 (1991). 
without at least a perception of crisis. If true, this is unfortunate. Rapid responses under crisis conditions can hold poor long-term promise, and they may delay introduction of better solutions after an approach to reform has commenced under a flawed agenda. The current diminished sense of urgency could make this time especially auspicious: there is enough concern to assure continued exploration for solutions without a sense of panic that might provoke inappropriate responses in the search for immediate solutions. By the same token, it is important that the improved responses be readily available when the next crisis begins.

The following agenda is based on the assumptions that this is a time when reflection can continue in an atmosphere of diminished pressure, and when virtually all affected parties are now concerned less with symbolic change than with reaching identifiable goals. The items are not ordered by importance; instead, they constitute an integrated approach to what might be described as evolutionary change.

\section{A. An Agenda in Outline}

1. Continue to Develop Useable Knowledge About Malpractice. There is still much to learn about the nature of malpractice and the problems associated with current legal responses. If funding for information gathering and analysis were to "dry up" at this stage, it would be a major blow to future reform. Already it has been recognized widely that the problems of malpractice are not confined to the legal system. Further research will have an additional role of helping the medical community continue to fashion new and refine existing measures designed to lessen the incidence of medical injury.

2. Undertake Trials and Demonstrations of New Approaches. Undertaking trials and demonstrations of new approaches would be consistent with the view that "fine tuning" past reforms will be inadequate. Innovative legal responses are necessary if we are to deal fairly and efficiently with medical injury.

Until recently, few major proposals for change had reached the "postdrawing board" stage of readiness for formal demonstration projects. Today an increasing number are at or near that point, including a system based on compensating "compensable events." 83 Other candidates for this include neo-no-fault schemes and channeling of claims ${ }^{84}$ through hospitals. Some proposals may be so sweeping that demonstration projects would not be easily undertaken. The AMA and Medical Specialty Societies approach, for example, has many interesting features, but a demonstration seemingly would require the establishment of a major new claims resolution system even though a fault orientation is maintained. Such a massive change raises serious and perhaps unanswerable questions about its potential impact. In a climate

83. Tancredi \& Bovbjerg, 54 L \& Contemp Probs at 147 (cited in note 72 ).

84. See notes $63 \& 70$. 
characterized by concern about finances and wariness of change "for change's sake," introduction of such a major new mechanism is likely to be difficult. ${ }^{85}$

Demonstrations are not inexpensive, yet they seem a good investment. Most projects also will require governmental interest and commitment beyond financial support.

3. Review and Fine Tune Existing Statutes. As noted earlier, there is evidence that some legal reforms have affected claims and payments, while others have accomplished little or nothing. Some have even created obstacles to pursuing valid claims. As new, incremental changes are being considered or adopted, it seems important for states to eliminate measures introduced in the absence of adequate information if they have been established as unsuccessful. Similarly, many states can improve on their more effective provisions by analyzing the experience in other states that enacted different variations.

\section{Take Special Steps to Assure that Research Is Translated into New and Innovative} Approaches. Although the step that should follow information gathering and analysis is among the most important in the process of formulating responses, it could easily be overlooked. The research results must be translated into new and innovative approaches. Because of the complex issues involved in such an endeavor, interdisciplinary cooperation among the professions will be essential. A goal of producing truly innovative responses is unlikely to be reached simply by holding conferences or convening occasional committees, however distinguished the participants. It will instead require encouraging and offering released time and other essential support for experienced and imaginative individuals from areas including medicine, law, health administration, and economics to produce workable models that consider many different facets of our present legal and health care systems. Having

85. Researchers at Georgetown are studying the feasibility of implementing the AMA proposal. As part of their analysis, they commissioned papers from experts in various fields to gauge their reactions to the proposal. The papers provide an interesting blend of opinion. One point made is that the proposal represents a major advance over past negative approaches taken by organized medicine. See Randall R. Bovbjerg, Reforming a Proposed Tort Reform: Improving on the American Medical Association's Proposed Administrative Tribunal for Medical Malpractice, I Courts, Health Science \& L 19, 20 (Georgetown U Med \& L Ctrs, 1990). See generally Mary Ann Baily, The Administrative Approach to Medical Malpractice Disputes, 1 Courts, Health Science \& L 29 (Georgetown U Med \& L Ctrs, 1990) (suggesting that the AMA approach would likely result in a clearer enunciation of the standard of care); Laura L. Morlock, An Assessment of Potential Impact on Claims Resolution and the Quality of Medical Care, 1 Courts, Health Science \& L 35 (Georgetown U Med \& L Centers, 1990) (noting that the success of Maryland's pre-trial screening panel indicates that the basic premise of the AMA proposal is sound). The concerns expressed include whether the Board would possess the necessary resources and commitment to enforce the negligence standard effectively, and whether it would be sufficiently impartial. See Baily, The Administrative Approach at 31 (cited above) (questioning adequacy of financing); Bovbjerg, Reforming a Proposed Tort Reform at 22 (cited above) (questioning independence). Not surprisingly, the paper prepared by a representative of the plaintiffs bar was highly critical; the author opined that the proposal was unconstitutional, unfair, unsound, and in the final analysis un-American. J. Douglas Peters, Critique of the American Medical Association's Model Medical Liability and Practices Reform Act, 1 Courts, Health Science \& L 5l, 55 (Georgetown U Med \& L Ctrs, 1990) (" $[T]$ he act's design is fatally flawed and probably irreparable .... [O]nly kamikaze legislators will ride in this Zero."). 
good research in hand does not mean that producing statutory responses becomes a simple or perfunctory process.

5. Selectively Make Further, Incremental Changes. In addition to continued fine tuning of existing provisions, a number of changes could be considered for introduction without further demonstrations. Several alternative dispute resolution procedures provide perhaps the best illustration.86 Also to be considered are variations on existing, limited no-fault approaches such as those adopted in Virginia and Florida.

Incremental new changes at this stage should be carefully evaluated in advance in accordance to what it is expected to accomplish and what evidence exists that it may successfully fill that expectation.

6. Continue to Review the Need for More Revolutionary Changes. Of proposals under serious discussion, an administratively operated, no-fault scheme for serious injuries would effect the most sweeping change. Such a scheme was under serious consideration in New York recently. ${ }^{87}$ However, in his 1991 State of the State address, Governor Mario Cuomo retreated somewhat by announcing that only a birth-related, no-fault scheme would be introduced for legislative consideration this year. ${ }^{88}$ Nevertheless, serious calls for such a system continue to be made.

Comparisons of costs of the medical injury compensation system in New York in 1984 and California in 1974 indicate that the prospects of devising an economically feasible system are much greater today. As time goes on, it also may be considered more socially desirable. While the current political and insurance climates would indicate that legislatures are unlikely to feel sufficiently pressured to install such major change now, in the next "crisis" it may hold far greater attraction. Indeed, the gradual evolution of limited "nofault" schemes may be the evolutionary forerunners of such a larger system.

\section{B. Who Should Take the Initiative to Implement an Agenda?}

An issue now being debated more frequently is whether medical malpractice liability should remain largely within the purview of state regulation or whether the federal government should further expand its role. The issues may be more political than legal. Despite a spate of recent legislative initiatives, ${ }^{89}$ federal preemption in even part of an area such as

86. See, for example, Metzloff, 54 L \& Contemp Probs at 104-14 (cited in note 25).

87. Indeed, exploring the feasibility of such an approach was considered one of the purposes of the Harvard Medical Practice Study. See note 19.

88. See Malpractice Reforms Outlined by Cuomo, NY L J 1 col 5 (January 11, 1991).

89. See, for example, the Medical Injury Compensation Fairness Act of 1991, S 1232, 102d Cong, lst Sess (June 6, 1991) (introduced by Sen Domenici); Health Care Liability Reform and Quality of Care Improvement Act of 1991, S 1123, 102d Cong, Ist Sess (May 22, 1991) (introduced by Sen. Hatch); Ensuring Access through Medical Liability Reform Act of 1991, S 489, 102d Cong, 1st Sess (February 26, 1991) (introduced by Sen. Hatch); Medical Malpractice Dispute Resolution Act of 1990, HR 4566, 101 st Cong, lst Sess (April 19, 1990) (introduced by Rep. Nancy Johnson). For a discussion of the Domenici bill, see Clark C. Havighurst \& Thomas B. Metzloff, S. 1232-A Late Entry in the Race for Malpractice Reform, 54 L \& Contemp Probs 179 (Spring 1991). 
torts is likely to be opposed by many states. A more palatable federal role in the near term probably would be to require state adoption of certain minimum provisions for change, using Medicare and Medicaid financing as the pressure point. This could allow states flexibility to experiment. Whether or not malpractice is to remain largely within state control, the need for workable models will remain.

\section{How the Agenda Might Change}

Several identifiable factors could make this agenda obsolete quickly. One factor would be major restructuring of the tort system, or some significant part of it, independent of medical malpractice concerns. Successful introduction of a health care scheme with universal access could serve as a catalyst for broader and more rapid change. Because of the growing consensus of need to expand such access, this is a realistic development to anticipate. While tort reform might not necessarily accompany such change, increasing access could reinforce the search for better responses to medical injury and exert even greater pressure on costs. For example, the two could be regarded as appropriate for inclusion jointly in any broad legislative package. Or if medical injury and its attendant costs and complexities were deemed an obstacle to expanding access, it could be considered necessary to deal with it. ${ }^{90}$ The choice of approach for expanding access thus could significantly affect both the perception of need for medical injury reform and the means for achieving it. While medical injury reform did not accompany introduction of a national health care system in England, there was considered no need at the time. Recently, however, a system of Crown indemnity has been introduced.

\section{VI}

\section{Conclusion}

As long as the liability insurance climate improves, it is doubtful that state legislatures or the federal government will feel significant pressure to pursue major medical malpractice liability reforms, though continued rumblings of serious concerns should sustain attention on at least some of the many fronts for reform. The most important strategies likely to be accepted in the near term can be characterized as moving us forward in an evolutionary fashion. Such additions would supplement the present system and also might be incremental steps toward a much different system of dealing with medical injury. Perhaps the most important consideration is for us to take advantage of the "non-crisis" atmosphere of the day. If there is no renewed "crisis," we

90. Other potential scenarios would vary with the choice of scheme for expanding access. For example, if health insurance, public or private, were deemed the appropriate course, issues would arise of whether there would be subrogation of the program to the claim for health care required by malpractice or, alternatively, whether such payments would be the only recovery, with malpractice actions ceasing to exist in most cases. Compare George J. Annas, Barbara F. Katz \& Robert G. Trakimas, Medical Malpractice Litigation Under National Health Insurance, 1975 Duke L J 1335. 
will have lost little by doing so. If acute pressures reappear, as seems most likely, we will find ourselves prepared to respond with less flailing. ${ }^{91}$

91. See Bovbjerg, 22 UC Davis L Rev at 556 (cited in note 8) ("One can hope that reform issues will not now ebb in the late 1980 s as they did in the 1970s; it would be encouraging to meet-or even to preempt-the next crisis with more information and a better game plan."). 
